\title{
Correction to: Microwave Dielectric Properties and Reduction Behavior of Low-Grade Pyrolusite
}

\author{
FEI HE,${ }^{1}$ JIN CHEN, ${ }^{1,2,6}$ GUO CHEN,,${ }^{1,2,3,7}$ JINHUI PENG, ${ }^{1}$ \\ C. SRINIVASAKANNAN, ${ }^{5}$ and ROGER RUAN ${ }^{2,4}$ \\ 1.--Key Laboratory of Unconventional Metallurgy, Ministry of Education, Faculty of \\ Metallurgical and Energy Engineering, Kunming University of Science and \\ Technology, Kunming 650093, People's Republic of China. 2.-Key Laboratory of Green- \\ Chemistry Materials in University of Yunnan Province, Yunnan Minzu \\ University, Kunming 650500, People's Republic of China. 3.-Hunan Provincial Key Laboratory \\ of Efficient and Clean Utilization of Manganese Resources, Central South \\ University, Changsha 410083, Hunan, People's Republic of China. 4.-Center for Biorefining, \\ Bioproducts and Biosystems Engineering Department, University of Minnesota, 1390 Eckles Ave., \\ Saint Paul, MN 55108, USA. 5.-Chemical Engineering Department, Khalifa University of \\ Science and Technology, Abu Dhabi, UAE. 6.-e-mail: jinchen@kmust.edu.cn. \\ 7.—e-mail: realchenguo@aliyun.com
}

\section{Correction to:}

JOM, Vol. 71, No. 11, 2019

https://doi.org/10.1007/s11837-019-03522-8

Corresponding author designation is missing for Jin Chen in the original publication of this article. It is corrected here.
Publisher's Note Springer Nature remains neutral with regard to jurisdictional claims in published maps and institutional affiliations. 